\title{
The Foreign Policy of Cities
}

\section{Introduction}

One of the most significant trends of the last decade has been the increasing prominence of cities on the world stage. 'Global' cities have developed a size, scope and reach that commands increasing weight in global issues. One result of this is that cities have begun to develop forms of diplomatic activity that seek to translate their increasing importance and growing capabilities into influence on aspects of global governance. With hundreds of formalised city networks, regular appearances at (and increasingly active roles in) major multilateral frameworks, as well as a now wellestablished recognition by the media, the foreign policy of cities on the world stage can no longer go unnoticed.

Yet this is a development that often drops off the radar of many scholars and practitioners of International Relations. This is because foreign policy has long been the unchallenged preserve of the state, heretofore the only entity with the legitimacy, authority and capacity to pursue a foreign policy.

Yet scholars and practitioners are now progressively supporting the idea that cities, too, can conduct international relations and 'diplomatic' activities. ${ }^{i}$ This is by no means simply an academic endeavor: the well-known C40 Climate Leadership Group, which gathers 96 of the world's largest metropolises representing $25 \%$ of world GDP, has a dedicated 'city diplomacy' team, and the World Health Organization has developed a city health diplomacy agenda as part of its Healthy Cities Network, to name but two of the many examples here.

Building on this recognition for the value of thinking of cities not just as locallybounded actors, we consider the 'foreign policy' of cities to consist in a city's formal strategy in dealing with other governmental and non-governmental actors on an international stage. ${ }^{\text {ii }}$ If aligned in logic to the traditional notions of 'foreign policy' circulating in International Relations theorizing (IR), the foreign policy of cities is however, to some degree, unlike that of states in that it relies even more extensively on specific forms of "network power" - the ability to convene and lead coalitions of actors towards specific governance outcomes - and far less on sovereign forms of power. ${ }^{\text {iii }}$ This form of power is increasingly important in emerging regimes of global governance that characterize the shifting ground of international politics in the twenty-first century.

In this article we show how and why cities increasingly flex their economic and political muscles. We look at the historical drivers that have generated new capacities for increasingly transnationally connected global cities. We then examine the diplomatic practices of cities today, and the different mechanisms, channels and capacities that enable those practices. We discuss some of the constraints cities face in developing foreign policies, as well as the differences between city diplomatic activity and traditional state foreign policy. Finally, we look at the different outcomes cities may pursue via their diplomatic activities, and discuss the significance of city diplomacy trends for how we think about the international system. 
Running through the article is a tension that needs to be resolved at some point in the coming decades: a tension between cities that are globally connected, have transnational reach, are close to their citizens, and wield novel power in global governance, and the traditional state based logics of an international order that formed in a different age.

\section{The Drivers of City Diplomacy on the World Stage}

To speak of a 'foreign policy' for cities has really only become a meaningful question in the last decade or so. This is because cities have undergone a profound transformation over the last half century, the effects of which are now beginning to be felt. The scale, significance and capabilities of cities have been transformed by the political, economic and technological forces that we associate with contemporary globalization. As these forces transformed cities, cities in turn became central driving forces in the expansion of economic globalization, most crucially as sites of economic governance. The contingent inter-play of political, economic, technological and demographic trends in this period has generated new roles and capabilities for major cities. It is on this bedrock that cities have begun to translate their new status and changing governance capabilities into political objectives.

An extensive literature on 'global cities' has emerged as an ongoing attempt to understand the nature of contemporary urban change. ${ }^{\text {iv }}$ In particular, it has sought to understand the new role that cities began to play in the global economy after its restructuring in the 1970s. The collapse of the post-war 'Bretton Woods' framework of rules and institutions underpinning international commercial and financial transactions in that decade, and its replacement by a broadly neoliberal system ${ }^{\mathrm{v}}$ of free markets and reduced capital controls, generated a new economic environment in which certain key cities became key strategic sites for economic governance. These regulatory changes, sometimes referred to as the 'Washington Consensus', had the effect of supercharging global financial markets, relocating production to the cheaper labour markets of the developing world, and kick-starting a great expansion of the multi-national corporation. The advent of new digital information and communications technologies also facilitated this process of reorganizing global production. This heralded the creation of a new economic order in which the state retreated from many of the tasks of determining economic activity. It generated an economic governance gap that was filled by private firms operating from the central business districts of cities such as New York, Hong Kong or London, which became increasingly densely connected trans-national hubs of economic decision-making capabilities. ${ }^{\mathrm{vi}}$

These connections 'super-charged' certain cities, which used their inherent historical and economic advantages (in particular, the dynamics of urban agglomeration) to draw in much of the wealth and resources of the global economy. The scale of these dynamics has begun to reshape the planet. The United Nations has extensively documented how the number of cities in the world with populations greater than 1 million increased from 75 in 1950 to 447 in 2011, while during the same period the average size of the world's 100 largest cities increased from 2 to 7.6 million. In the decade between 1990 and 2000 alone there was a 30\% increase in the size of urban 
settlements in the developed world and a 50\% increase in the developing world. Such a demographic earthquake represents a qualitative and quantitative shift in human society, generating urban entities of a size and scope to rival all but the very largest states. In fact, several urbanists argue now that cities are so prominent on a global scale that we should be really speaking of 'planetary urbanization', and that no corner of the Earth is free from the influence of the urban. ${ }^{\mathrm{vii}}$

Despite the key role of global economic restructuring in generating urban transformation, we should note that this form of economic globalization was also profoundly political. The creation of the global market in which cities have thrived has been underpinned by a geopolitical order shaped by US hegemony. ${ }^{\text {viii }}$ Global cities expanded rapidly in the 1990s after the collapse of the Soviet Union, as the liberal world order extended its reach.

One further driver of city influence on the world stage has become increasingly significant in recent years. It is related to the scale at which many of the most pressing problems of world politics now exist. Issues such as climate change, transnational terrorism or financial regulation need to be tackled at the global scale. But the international society of states finds itself increasingly unable to efficiently govern this global complexity.

It is here that cities offer interesting new possibilities for new forms of twenty-first century global governance. By coming together in transnational networks, cities have offered the possibility of an emergent political assemblage that can offer forms of governance that can match the scale and complexity of global challenges. The new technical capacities offered by digital networks have meant that it is increasingly possible for mayors to straddle the local and the global scales. This had led to the formation of many new transnational metropolitan networks, aimed at various forms of global governance. They operate at a variety of different scales: from the national, regional, to the transnational, and with various aims and levels of effectiveness.

Some of our recent empirical research has evidenced the increasing influence of "city networks". ix It is undeniable that a marked growth in these city-to-city diplomatic initiatives can be detected over the last two decades: if at least 60 were active in 1985, this number had nearly doubled by the late 1990 s (circa 120 by 1999) and again by the early 2000s (circa 200 by 2009), and, as noted above, it seems to be growing steadily today somewhere between 250 and 300 organised associations of cities globally. ${ }^{x}$ Since the early 1990 s, in particular, international relations have seen the emergence of major international efforts like ICLEI Local Governments for Sustainability, which has been foundational in including a 'local' emphasis on the UN sustainable development framework of the 1992 Rio summit and its 'Agenda 21'. This has even accelerated in the last decade, with the emergence on the international scene of, for instance, the aforementioned C40 (founded in 2005) which has had a prime spot in the development and implementation of the Paris Agreement on climate change; of UCLG (United Cities and Local Governments, founded in 2004) which plays a key role in many UN frameworks; or the Rockefeller 100 Resilient Cities initiative (2013) that has channelled over $\$ 100 \mathrm{~m}$ in direct investment to strengthen resilience planning in cities. 
Transnational governance networks such as these represent a vast scale jumping planetary network, linking local actions to global governance outcomes, independent of state government activities. In this article we give specific focus to global networks, such as the $\mathrm{C} 40$, which have a transnational reach, and enrol multiple agents (Transnational Corporations, Non-Governmental Organisations, the UN system). As we noted in other research, these are by no means just networks of 'Northern' or 'Western' cities: they cover a vast variety of topical foci beyond the environment, and span the globe in many varied ways, constituting today a central force when it comes to networking local governments beyond their local remits. ${ }^{\mathrm{xi}}$

We are seeing, increasingly, a move from cities to extend their impact on the global stage from economic governance to political governance. This deep-lying tension within the structure of international society is why the issue of the strategic direction and policy orientation of cities is increasingly important. But it also generates a growing tension between cities and states, and problematizes a relationship that has been settled in a specific way since the advent of Westphalian sovereignty - since when the city has been increasingly internalized within the state. The new capacities of cities offer the prospect of this relationship being renegotiated - and we need to see if states and cities will be partners in global governance or whether they will increasingly come into conflict with each other - as they have, for example, with the Trump administration's withdrawal from the Paris Agreement on climate change. ${ }^{\text {xi }}$

In the next section we examine some of the existing practices of cities on the international stage, before returning to this increasingly problematized relationship between the city, the state and global scaled governance.

\section{The Diplomatic Practices of Cities}

If we consider the international muscle that cities might have in world affairs, we must see cities not as passive 'venues' for international relations, nor as a purely subjugated context of 'higher' politics. On the contrary, local governments can be effective actors shaping the dynamics of global governance. Certainly, the rhetoric espoused by most of the major global advocacy initiatives involving cities, such as Mayors for Peace or the Global Covenant of Mayors, tends to demonstrate this capacity to go beyond their local purview. ${ }^{\text {xiii }}$ The extent and persistence over the last two decades of the internationalisation of city-led initiatives is a clear sign that cities can partake actively in the architecture of world politics beyond inter-national relations. $^{\text {xiv }}$

A typical representation of this is the often-cited assertion that, while "nations talk, cities act". Variously attributed to a number of city leaders, the statement embodies much of the ethos of the leadership of former Mayor of New York, Michael Bloomberg, in his tenure (2010-2013) as chair of the C40 Climate Leadership Group. In short, cities are 'out there' in world politics, lobbying, linking, planning and cooperating.

The capacity to link transnationally, negotiate and collaborate with both multilateral and multinational private worlds, and carry 'international' agendas is, as we have seen, increasingly crucial to addressing global challenges like climate, migration, health and resilience, which increasingly transcend national borders and the capacities 
and political will of states to address them. ${ }^{\mathrm{xv}}$ Today, an important portion of these hundreds of city networking activities can be identified as "city diplomacy", which we define as: mediated 'international' relations between rightful representatives of polities (cities in this instance), that result in agreements, collaborations, further institution-building and cooperation across boundaries. ${ }^{\mathrm{xi}}$ For instance, within the framework of networks like C40, 'ambassadors' of cities (elected mayors, or their peers) such as London or Seoul negotiate common frameworks and partake in collective action on behalf of their urban dwellers. Normatively, they create joint commitments like the 2010 Mexico City Pact on Climate or the 2009 Istanbul Water Consensus, and often do so in collaboration with multilateral organisations, as with the case of the World Health Organisation and the 2016 Shanghai Consensus on Healthy Cities on the implementation of SDGs in health at local level. But this goes beyond frame development into implementation, funding and assistance. UCLG and C40 have for instance recently convened an 'Urban20' within the context of the 2018 Group of 20. ICLEI has supported the implementation of a 'Cities' dimension of the Intergovernmental Panel on Climate Change (IPCC), now including a specific cities special report in its $7^{\text {th }}$ assessment. Eurocities has been a key voice in the development of an Urban Agenda for the European Union. The examples are many and increasing.

All of this evidence points at the city's capacity to connect and focus different actors, catalyse action by networking, and deploy the powers of collaboration. This is of course a quite different form of power to the more familiar and traditional model of sovereign state power. Wielding network power means that, in practice, the city's influence is never really stabilised, and is always shared with other actors, peers and flows. This is a peculiar positioning that cities currently enjoy in the complex landscape of global governance. As Mikael Roman pointed out, cities can now govern "from the middle": they are not intrinsically bound by the 'high politics' of relations among nation-states, and yet neither are they bottom-up or NGO-like actors (contra some often misleading accounts). ${ }^{\text {xvii }}$ This position not only empowers cities - it also offers a potential avenue out of the impasse that state diplomacy often finds itself in when it comes to questions of collective action and the global commons. City networks offer a new channel to pursue governance outcomes - and the C40, for example, has generated a number of very specific governance solutions to climate change where states have been stuck at the negotiating table. In the case of the C40 such outcomes include developing joint coordination, sharing best practice and technical know-how in areas such as transportation, energy and waste infrastructures, and retrofitting projects. The C40 has stimulated over 14,000 climate actions amongst its members over the last six years. ${ }^{\text {xviii }}$ WHO Healthy Cities networks (e.g. in Europe or in the Asia-Pacific) are taking practical and applied steps to include health priorities across sectors in local policymaking.

Local governments, and their city leaders, have helped to accomplish unprecedented rates of globalization. But they remain, at present, firmly ensconced in a broadly neoliberal discourse in which the competitive and entrepreneurial city vies uncomfortably with collaboration. They are also partially responsible for the growing entrenchment of the private sector in service or infrastructure delivery. They are pivotal to contemporary geographies of global governance. City networks like the C40 also flag that we are now witnessing a shift in the direction of city foreign engagements. For decades, especially during the Cold War, cities' international 
relations were mostly limited to peer-to-peer cooperation. Now we see the return of more explicitly entrepreneurial, public-private 'hybrid' urban policies (a development that invites historical parallels with pre-modern city-states). Traditional twinning organizations, such as Sister Cities International (SCI), have themselves stepped away from more specific "city-to-city cooperation" (between cities) to a wider "city diplomacy' (between cities and other non-municipal actors). ${ }^{\text {xix }}$ Networks (such as SCI) are shifting, moving from an emphasis on the importance of twinning to an emphasis on the importance of strategy and alliance capability. ${ }^{\mathrm{xx}}$ The form and orientation of current city networks has therefore been going well beyond twinning: city networks are being constructed in partnership with actors other than municipal governments, such as the UN, the World Bank or the EU, and are increasingly intertwined with the cross-national action of the private sector. In some cases, the private sector can even be the initiator of such city networking efforts.

This is exemplified by the case of New York's city diplomacy, which puts entrepreneurial communications at its heart. In New York Foreign Affairs is conducted mainly within the Office of the Mayor by a dedicated Commissioner for International Affairs, whose main role is therefore to act on behalf of the Mayor in liaising with the various international actors. On one hand, the Office manages relations with the hundreds of consulates and international organizations housed in the city. This is a form of informal diplomacy whereby the city exerts its influence on international governments through the well-coordinated and deliberate welcome it gives them. On the other hand, the office also oversees a not-for profit organization called Global Partners Inc., set up by the city to upscale its old 'sister city' system. Testimony to the confidence and handling that major cities now have of the contemporary neoliberal order is the fact, for instance, that New York approaches this side of its international diplomacy like a corporate consultancy. Though located inside the Mayor's Office for International Affairs, the organization has its own independent board of directors charged with managing the institution effectively and profitably. Together, they coordinate a number of Global Partners Inc. summits and conferences as well as a large youth program aimed at fostering informal diplomacy through young people. To an extent, then, we can note a move in the direction of privatization of city diplomatic activity, which goes beyond both the mayor's office and local government. This type of city diplomacy takes on an entrepreneurial character, shaped by the dominant discourses and practices of liberal world order.

\section{Constraints on City Diplomacy}

Despite being empowered by the current configuration of world politics, cities also face various constraints. Cities, as Jennifer Robinson puts it, exist in a "world of cities". This consideration presents a key limitation to the collaborative spirit that the foreign policy of today's urban settlements might take in a world that, whilst made of cities, is also still solidly hinged on a global order based on markets, limited resources and competition. This means, in practice, that cities are often treading a fine line between collaborative, networked, efforts (like Mayors for Peace, the Metropolis network of major metropolitan areas, or United Cities and Local Government) and pressing local needs to maintain their cities as attractive and economically vibrant on a global stage. So, for instance, while the slogan '\#LondonisOpen' shows London's desire to lead global cities in internationally collaborative initiatives like the C40 
Climate Leadership Group, London's strategy is also to remain an "internationally competitive and successful city", envisaging itself as a prime global placing for business, innovation and market hubs. In this sense cities seem today to be walking a fine line between competition and collaboration with other cities, if not with international actors more generally. A key determinant of this behaviour, of course, is the well-recognised state of resource constraint that cities are currently operating in often unable to capture their own tax base, set their own budgets autonomously, or break out of the legal frameworks set by state legislatures.

A similar consideration on the fine balance between competition and collaboration can be made for the relationship between cities and states. Does the 'rise' of the city imply the demise of the state? If cities are catalysing international efforts, and if they have a millennial legacy of global engagements, will we then do away with international institutions? Globally visible mayors like Michael Bloomberg have, in the past few years, publicly criticised international processes in opposition to the real, pragmatic actions of city leaders. For instance, in a 2011 interview with the BBC, Bloomberg reiterated that, at the "national, international and state levels," there is "an awful lot of hot air" on climate change, and declared that "it is up to mayors" to solve environmental problems. ${ }^{x x i}$ If we account for the thousands of climate actions undertaken in Bloomberg's city network then (C40 Cities), and multiply that by at least two hundred similar city networks efforts by city leaders, cities might have a case that they can fill the governance gaps that states have failed to plug. We can find a further example of cities utilising transnational networks to bypass inadequate state governance provision in the realm of security. For example, after September $11^{\text {th }}$ 2001, the city of New York responded to what it perceived to be the failure of the state to adequately protect it by fostering global security governance networks, seeking to develop its own institutional capacities for counter-terrorism, and developing transnational intelligence gathering capabilities in collaboration with other municipal authorities around the world. ${ }^{\text {xxii }}$

Does this mean, then, that we are set up for an epochal confrontation between cities and states? Or, rather, is this a time ripe for collaboration between national and local governments? While the former, more sensationalist, option has gained some currency in media and academia, and with the rhetorical flourishes of some mayors, it might be the more measured latter case where the current role of cities in global order holds most promise.

Interestingly, Bloomberg himself, along with several other mayors, more recently adopted the latter tone. In his 2015 Foreign Affairs article on the "city century", he in fact asserted that cities cannot replace the nation-state in pursuing solutions to poverty, security, disease, or trade. Rather he noted: "city leaders seek not to displace their national counterparts but to be full partners in their work - an arrangement that national leaders increasingly view as not just beneficial but also necessary." At least in the short to medium term, we need not pit cities against states, but think of cities and states: a critical collaborative juncture in which cities can lead a transformation of ageing international institutions and set a roadmap beyond state-centric gridlocks.

An initiative like the 'Urban20' speaks of this more collaborative city/state spirit. Yet we should not forget the confrontation spurred by, for instance, populist and conservative movements in the UK and US, to name but two, where the Trump White 
House withdrawal from the Paris Agreement on climate change, or the May government's Brexit plan, have led to vivid reactions by coalitions of mayors and local leaders that seem to pit major 'global' cosmopolitan and 'open' cities against reactionary national governments. So, whilst the tone of collaboration might have been swinging in the direction of greater city/state partnership in the past decade, the (geo)politics of states and state-centric international relations might, in 2018, have set back greater alignment where it might be most needed.

\section{The Goals of City Diplomacy}

As cities increasingly realise their political and economic governance capabilities and growing strength, it becomes important that they have a clear direction and strategy for what they want to achieve. At present, this is largely lacking. Nascent forays by local and metropolitan authorities into global governance and city diplomacy currently focus largely on single issues such as climate change, health or security, have emerged in an ad-hoc fashion, and tend to be driven by technocratic agendas. One reason for this is that, as we have said, cities are often competing for resources as much as they are testing co-operation via networks. Finding broad, strategic goals in common can be difficult in this mixed context. There remain very limited efforts at strategic alignment between sectors, and at strategic thinking, when it comes to developing coherent foreign policies by cities big and small, where opportunism still reigns as the main modus operandi in city diplomacy.

In this section we conclude by examining the policy goals that cities are pursuing, via the multiple governance channels we have mentioned. We distinguish between short, medium and long-term timeframes. This enables us to move between immediate goals that cities are currently pursuing, and more longue duree structural shifts in the international system that forays into city diplomacy and global governance might signify. The rise of city diplomacy is not simply about sub-state politics. We submit that it is far more significant than that: it is an indication of a more significant structural shift in the foundations of international society, driven by those factors we identified earlier as driving global city formation.

In the short term, cities are very much concerned, as they always have been, with governing the everyday and the mundane. At the same time, capturing economic growth and attracting talent and resources into the city is also at the core of urban strategies - and this places cities into competition with each other for finite resources. More recently cities have pursued eye-catching global governance outcomes in issues such as climate change, resilience, health, security via transnational networks and public private collaboration, as we have seen. These efforts are sometimes parallel to traditional state diplomacy, but often they engage with international organizations and states. Moreover, cities are increasingly recognised within the UN system not just as places for action but as actors and partners in their own right. Aligning themselves with the UN's Sustainable Development Goals (SDGs) seems to be, in the short term, the closest that cities have come to articulating a collective policy direction.

A tangible expression of this is the United Nations' New Urban Agenda that emerged from the Habitat III conference in Quito in 2016. ${ }^{\text {xiii }}$ The New Urban Agenda captures the twin goals of market led economic growth and development, and the desire to 
produce more socially just and sustainable cities - setting out aspirations (often falling short of implementation) around equality in urban settings, environmental sustainability and resilience, poverty reduction, and liveability. Reconciling these two impulses - growth and social justice - is going to be perhaps the core challenge of the twenty-first century. But Quito provided very few answers for reconciling the tensions between them. In fact, it is increasingly the case that attention to the New Urban Agenda has been fizzling out, as the broader discourse of the SDGs, but also specific agendas around climate change or cooperation in the wake of populist nationalism, have been taking over the spotlight.

However, the ability of frameworks like the SDGs, New Urban Agenda, and parts of the Paris Agreement or the Sendai Framework for Disaster Risk Reduction, to orient efforts at urban development show the importance of the UN System in coordinating and catalysing city diplomacy at the present moment. At the same time, and continuing to reflect our theme of tension between city networks and state based diplomatic logics, the increasing prominence of cities within the UN system has also sparked tensions with states such as Russia, who see it as a dangerous precedent indicating the possible erosion of the principle of state sovereignty. ${ }^{\text {xxiv }}$

In the medium term we might envisage that cities begin to embody the principles of these agendas in their material forms, shaping both the agendas and themselves in the process. There is recognition of the need to reshape cities to meet the challenges of the twenty-first century, via new forms of governance, repurposing technologies, and harnessing the power of design. So we hear much about ambitions to generate Smart Cities, Resilient Cities, Sustainable Cities and Healthy Cities. Strategies to attempt to generate such idealised urban forms represent key medium-term governance goals for cities' networked diplomacy.

Finally, in the longer term, it is not inconceivable that these developments might signal a very significant structural tension between the growing weight of cities, and the fading strength of the territorial sovereign state. We have noted the multiple signs of this tension in the contemporary city/state relation. But decades from now this issue may be far more prominent. There is also a growing tension between a citybased political order and state-based institutions like the UN, where the role of cities remains opaque and potentially destabilizing of established norms and procedures.

Some of the larger cities and urban regions have, in recent decades, generated astonishing levels of growth and economic power, are linked transnationally by the most advanced technological infrastructures on the planet, have reach that stretches across traditional state boundaries, and have populations so large that they begin to destabilise traditional understandings of what international politics is. Cities are beginning to realise their power in both economic and political governance, and act as important 'norm-entrepreneurs': generating some of the normative content and aims behind emerging global agendas such as sustainability and resilience. A global network of thousands of linked cities affords a vast reservoir of human capital and creativity that will develop in unexpected directions in this century.

Some have speculated that perhaps one of those long-term directions will be the development of new forms of political life that finally challenge the territorial nationstate as the locus of modern life and legitimacy, and can offer solutions that match the 
multi-scalar nature of the governance challenges of an increasingly planetary politics. Might we eventually see the emergence of some form of historically novel political assemblage that can unite the various scales of governance, from the local to the global, more effectively, and more democratically, than states have managed something like Benjamin Barber's 'Global Parliament of Mayors'?

Such a world is certainly not imminent. Equally, states and state-centric processes are still very much in the driving seat when it comes to global frameworks and agendasetting. The role of large private and philanthropic sector actors in both shaping this system as much as often facilitating city diplomacy should not be underplayed. But what is increasingly clear is that cities can, and increasingly are, playing a key role in the international system as it adapts to the complex global problems of the twentyfirst century. 
${ }^{\mathrm{i}}$ As for instance summarised in Van der Pluijm, R., \& Melissen, J. (2007). City diplomacy: the expanding role of cities in international politics. Netherlands Institute of International Relations (Clingendael).

ii This approach builds on extending traditional notions of foreign policy to cities understood as local governments, and thus simply applying well-established understandings of what accounts as policy in a 'foreign' context to another layer of government than the state. We adapt the definition here from Steve Smith, Amelia Hadley and Tim Dunne (eds), Foreign Policy: Theories, Actors, Cases, 1st ed., Oxford: Oxford University Press, 2008 ${ }^{i i i}$ We have discussed this more at length in Acuto, M. (2013). Global cities, governance and diplomacy: the urban link. New York, Routledge. On the distinction between network and sovereign power see more broadly Grewal, D. S. (2008). Network power: The social dynamics of globalization. New Haven: Yale University Press.

iv For a guide to the extensive literature here, see: Brenner, N and Keil, R. eds. (2006). The Global Cities Reader. London: Routledge

${ }^{\mathrm{v}}$ Basic elements of neoliberal ideology include: deregulation of markets, privatisation of public assets, reductions in progressive taxation, restrictions on labour organisation, encouragement of competition in both public and commercial sectors.

${ }^{v i}$ Sassen, S. (1991). The Global City: New York, London, Tokyo. Princeton: Princeton University Press.

vii Brenner, N. ed. (2014). Implosions/explosions: Towards a Study of Planetary Urbanization. Berlin: Jovis.

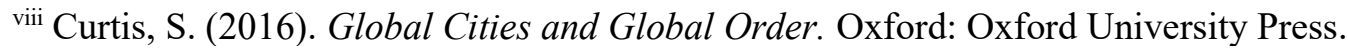

ix Acuto, M., \& Rayner, S. (2016). City networks: breaking gridlocks or forging (new) lockins?. International Affairs, 92(5), 1147-1166.

${ }^{x}$ Acuto, M. (2016). Give cities a seat at the top table. Nature, 537(7622), 611-613.

${ }^{x i}$ Ibid; also see Lauermann, J. (2018). Municipal statecraft: Revisiting the geographies of the entrepreneurial city. Progress in Human Geography, 42(2), 205-224; and Davidson, K.,

Gleeson, B., Cohene, L. and Acuto, M. (2018) Reconfiguring urban governance in an age of rising city networks: A research agenda, Urban Studies online first.

xii Gordon, D. J., \& Johnson, C. A. (2018). City-networks, global climate governance, and the road to $1.5^{\circ}$ C. Current Opinion in Environmental Sustainability, 30, 35-41.

xiii Mamadouh, V., Meijer, A., Sidaway, J. D., \& Van der Wusten, H. (2015). Toward an urban geography of diplomacy: Lessons from The Hague. The Professional Geographer, 67(4), 564-574.

${ }^{\text {xiv }}$ For instance: Bouteligier, S. (2013). Cities, networks, and global environmental governance: spaces of innovation, places of leadership. NewYork, Routledge; Schragger, R. (2016) City Power: Urban Governance in a Global Age. New York, Oxford University Press. ${ }^{x v}$ Johnson, C. A. (2018). Introduction: The Power of Cities in Global Climate Politics. In The Power of Cities in Global Climate Politics (pp. 1-23). Palgrave Macmillan, London.

${ }^{\text {xvi }}$ Chan, D. K. H. (2016). City diplomacy and "glocal" governance: revitalizing cosmopolitan democracy. Innovation: The European Journal of Social Science Research, 29(2), 134-160; . xvii Román, M. (2010). "Governing from the middle" Corporate Governance 10(1): 73-84.

xviii https://www.c40.org/blog_posts/from-copenhagen-to-paris-cities-and-mayors-are-leadingthe-way-on-climate-action : Accessed 24.10.18

${ }^{x i x}$ Baycan-Levent, T., Kundak, S., \& Gulumser, A. A. (2008). City-to-city linkages in a mobile society: the role of urban networks in Eurocities and Sister Cities. International Journal of Services Technology and Management, 10(1), 83-109.

${ }^{\mathrm{xx}}$ Buis, H. (2009). The role of local government associations in increasing the effectiveness of city-to-city cooperation. Habitat International, 33(2), 190-194;

${ }^{x x i}$ BBC News, Mayor Bloomberg: "Too much 'hot air' on climate change” 27 May 2011, available at http://www.bbc.co.uk/news/world-us-canada-13582351 
xxii Ljungkvist, K. (2015). The Global City 2.0: From Strategic Site to Global Actor.

Routledge.

xxiii The text of the New Urban Agenda is available at: http://habitat3.org/the-new-urbanagenda/: Accessed 24.7.18

${ }^{x x i v}$ Acuto, M. (2017) Cities are gaining power in global politics - can the UN keep up? The Conversation 14 September 2017, available at: https://theconversation.com/cities-are-gainingpower-in-global-politics-can-the-un-keep-up-83668: Accessed 24.7.18

${ }_{\mathrm{xxv}}$ Barber, B. (2013). If Mayors Ruled the World: Dysfunctional Nations, Rising Cities. New Haven: Yale. 